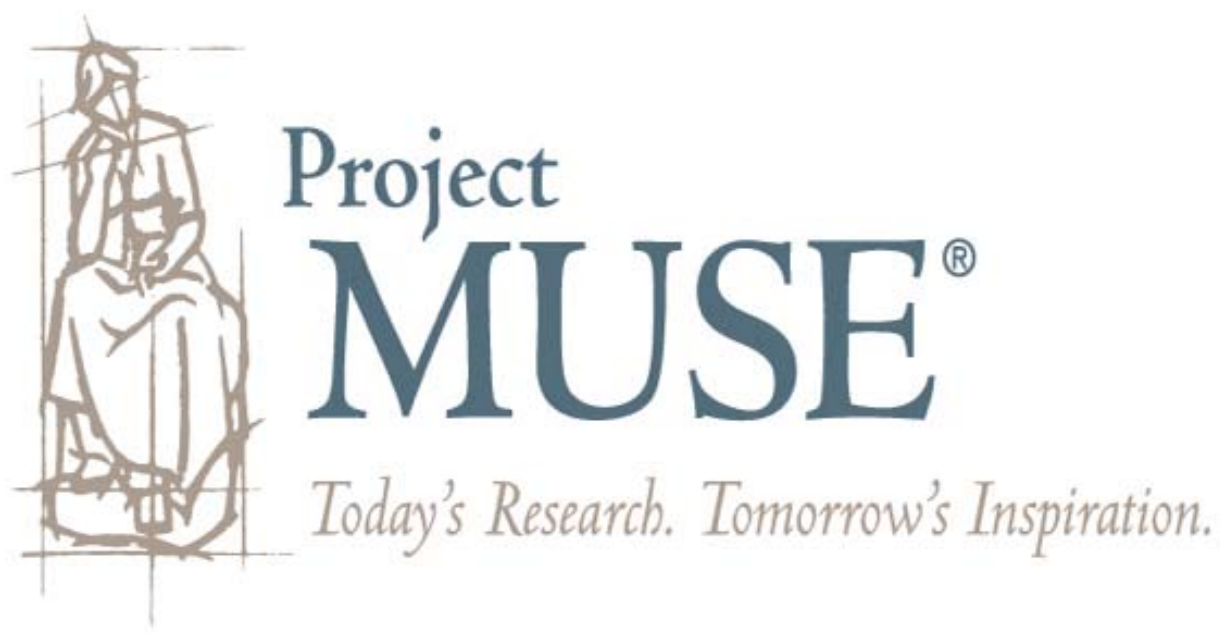




\title{
Opportunity for Whom?: Political Opportunity and Critical Events in Canadian Aboriginal Mobilization, 1951-2000
}

\author{
Howard Ramos, Dalhousie University
}

\begin{abstract}
Many social movement researchers question the usefulness of political opportunity as a concept. However, others argue that it can be refined by disaggregating different opportunities for actors and outcomes to understand the underlying mechanisms that influence each. This research extends this analysis by asking "political opportunity for whom?" Looking at Canadian Aboriginal mobilization, it assesses how different opportunities influence a broad range of movement actors and organizations. Using data from a 50-year period it assesses how contemporaneous, lagged and change regression modeling of opportunities affect results. The article finds that structural opportunities around resources robustly influence a wide range of mobilization.
\end{abstract}

Over the past 30 years social movement scholars have increasingly theorized how changing social and political contexts influence mobilization. Many have examined how changing legal structures, political institutions, sympathies of elites, or threat of repression and loss of power affect the strategies, potentials and rates of contentious actions and organization formation. Political opportunity theory has emerged as the dominant literature dealing with such issues. However, it has come under the scrutiny of a number of scholars who critically question its integrity. In an attempt to address such concerns, Meyer (2004) and Meyer and Minkoff (2004) propose a number of strategies for future research: to disaggregate outcomes and actors from one another and to examine how underlying mechanisms of opportunity operate across each. In doing so, they ask two important questions: political opportunity for what and for whom? Their scholarship addresses the former, but only theorizes and partially engages the latter. Thus, this research uses new data on Canadian Aboriginal mobilization, 1951-2000, to extend their analysis and ask "opportunity for whom?"

I would like to thank Suzanne Staggenborg, Steven Rytina, James Ron, Yoko Yoshida and the Social Forces editors and anonymous reviewers for their constructive comments. Thanks also go to Selom Chapman-Nyaho who assisted with some of the data collection and Paul Armstrong who assisted in the drafting of this article. The research was funded by Fonds pour la Formation de Chercheurs et l'Aide à la Recherche and the McGill Institute for the Study of Canada. Direct correspondence to Howard Ramos, Department of Sociology and Social Anthropology, Dalhousie University, 6135 University Ave., Halifax, Nova Scotia B3H 4P9, Canada. E-mail: howard.ramos@dal.ca. 
This research examines how structural, signaling and general political opportunities affect the actions of different types of contentious actors and organization formations. It also examines how different model specifications, accounting for lags and change, influence the impact of political opportunities on the actions of different movement actors and organization formations. The aim is to assess which opportunities work most consistently across different mobilizers.

\section{Political Opportunity}

Meyer (2004) notes that the first explicit use of political opportunity in social movement research was by Eisinger (1973), in his analysis of race riots in American cities during the 1960s. ${ }^{1}$ A key component of that conceptualization was to distinguish between "opening" and "closing" political structures. Eisinger (1973) argued that governments that are responsive to their citizens' needs and demands are indicative of open opportunity structures, and by contrast, closed structures are found in situations where power is concentrated and governments do not respond. He found that cities with mixed open and closed access to the dominant polity experienced increased protest, whereas those with more open institutions incorporated aggrieved citizens into mainstream politics. These findings are supported by Tilly (1978), who Meyer identifies as another key figure in the development of political opportunity theory. Whereas Eisinger focused on structural conditions alone, Tilly also examined choices available to activists seeking to optimize their claims in a given context. Tilly (1978) examines how contentious actors weigh the costs and benefits of mobilization, considering facilitation and repression by governments and power holders as well as opportunity to mobilize and threat of repression. As a result, he adds agency and instrumentality to the equation. Tilly finds that polities which provide political actors viable access decrease contention. However, he also concludes that those which are overly repressive prevent contention. He thus identifies a fine balance needed for mobilization, where the polity is open enough not to repress, but is too closed to incorporate the discontent. Key to both Eisinger and Tilly's conceptualizations is attention to changing political contexts.

Their conclusions are supported by contemporary scholarship. For example, della Porta (1995) looking at mobilization in Italy found that radicalization of tactics were associated with closing opportunities. Others also find that threat of repression or loss of power and resources (and perceptions of it) increased mobilization (Goldstone and Tilly 2001; Van Dyke and Soule 2002). However, some find the opposite. For example, McAdam (1982) concluded that increased access to political systems, divisions within elites, available allies and diminishing state repression all increased mobilization of blacks on civil rights issues. These findings are 
supported by Tarrow (1989), examining widespread Italian mobilization during the 1960s and 70s. Meyer and Staggenborg (1996) argue that movements can even alter political alignments and create opportunities. As a result, current research makes it difficult to discern whether closing or opening opportunities induce mobilization.

A number of recent articles have thus begun to re-examine the notion of political opportunity in social movement research. Some offer stinging critiques, arguing that the concept is "tautological, trivial, inadequate or just plain wrong." (Goodwin and Jasper 1999) Others fear it is in danger of becoming too broad (Gamson and Meyer 1996). The roots of these sentiments stem from concern with the widespread and often divergent uses of the term, which speaks to its popularity but leads to ambiguous empirical results. Some researchers find that political opportunities increase protest, contentious action and organization (Amenta and Zylan 1991; Van Dyke and Soule 2002); others conclude they are less important than factors such as gendered opportunities or resources (McCammon et al. 2001; Snow et. al 2005); and yet others find them inhibiting.

Articles by Meyer (2004) and Meyer and Minkoff (2004) are equally critical in their review of the political opportunity literature. However, they also offer suggestions on how to refine it and derive more consistent mechanisms of analysis. They do this by assessing a wide spectrum of the concept's usage and propose new means to develop, test and operationalize it. They find that the main problems with political opportunity stem from clumping together different definitions, measures, outcomes and social actors.

In sorting through contradicting conclusions, Meyer (2004) and Meyer and Minkoff (2004) argue that much of the inconsistency stems from the diversity of measures used to examine political opportunity. They note that specifications include aspects of government structures (Kitschelt 1986), public policy (McAdam 1982; Tarrow 1988, 1989, 1998), geography (Boudreau 1996), and relations to other movements (Meyer and Staggenborg 1996); and this is just to name a few. To Meyer and Minkoff's credit, rather than proposing a canonization of measures, they argue that the route to making political opportunity a viable tool for social movement research is by recognizing underlying patterns among usages and measures. To do this, Meyer and Minkoff (2004) suggest regrouping political opportunities along Eisinger and Tilly's initial conceptualizations. They recognize differences among structural opportunities, such as "formal changes in rules and policies affecting political access" (2004:1467), from signaling opportunities that activists and officials monitor as changes in the political environment that encourage mobilization or policy reforms (2004:1470); both are treated as movement or issue specific. Also considered are general opportunities that are both substantive and symbolic in importance, or affect institutional structures and perceptions of political context and are not necessarily movement or issue specific. Meyer 
and Minkoff hypothesize that difference in reported results stems from conflating each of these and treating them as the same.

They also discuss "opportunity for what?" On this front, they contend it is important to understand what responds to political opportunities, and encourage researchers to differentiate between outcomes and actors, both of which are influenced by political opportunities but in potentially different ways. Meyer (2004:136) identifies two broad outcomes, mobilization and influence. The ability to act contentiously, protest or organize are all examples of the former. McCammon et. al (2001:49) recognize that "most movement studies" have focused on such issues of mobilization, including movement emergence and development. Yet, they also note fewer studies have examined the broad range of outcomes that might fall under the domain of the latter; for instance, looking at the receptiveness of mainstream polities or elites to social movement agendas. On this front, a number of contemporary researchers have begun to examine the effects on policy outcomes (e.g., McCammon et al. 2001; Soule and King 2006). It therefore appears that Meyer (2004) is in line with this current shift of focus, arguing it is best to distinguish action and organization (mobilization) from political success or failure (influence).

In addition, Meyer and Minkoff (2004) question, "political opportunity for whom?" Following earlier scholarship, which recognized that a political opportunity for one social actor or movement may in fact work against another (Meyer and Staggenborg 1996), they also acknowledge that movements are broad coalitions of different constituents and organizations with interests that come together at certain times but diverge at others. Meyer (2004:140) develops this further by differentiating between two types of movement actors: consistent champions, who act regardless of political context, and strategic respondents, who weigh opportunities and act when optimum success is perceived. Accordingly, each actor responds differently to political opportunities.

Meyer and Minkoff (2004) assess their propositions by regressing measures of American civil rights protest, organization and policy outcomes on a series of structural, signaling and general political opportunities. They find that protest is influenced by issue specific dimensions of political opportunities, organization by signaling processes, and movement related policy outcomes are determined by structural elements (2004). They conclude that their findings are evidence for the need to develop more nuanced understandings of political opportunity.

\section{Extending Meyer and Meyer and Minkoff's Proposals}

My research seeks to build on their framework and extend their analysis in three ways: first by engaging the question of "opportunity for whom," 
which is theorized but underdeveloped by Meyer and Minfkoff; second, by looking at the role of "critical events" in mobilization; and third by questioning how time, change and opportunities are specified in regression models.

Unfortunately, despite asking the question "political opportunity for whom?" this element of their analysis remains underdeveloped. Meyer and Minkoff (2004) do not differentiate among different types of social movement actors or organizations in their empirical analysis. A political opportunity for local mobilizers may be different than for intermediate or large movement organizations. At the same time, however, some opportunities might be shared, influencing different types of actors and organizations simultaneously, and in turn creating even more widespread mobilization. In fact, as Tarrow (1998) identified, through the notion of cycles of contention, it might be equally useful to understand what increases overall action and organization across a movement spectrum, which can be examined only by disaggregating among a range of different movement actors and then assessing instances when all mobilize.

To capture this, it is useful to analyze what role "critical events," or opportunities that affect widespread contention, play in generating yet more contention. As Staggenborg (1993:320) argues, "social movements are event-driven insofar as critical events alter expectations and perceptions of threats, focusing or distracting the attention of movement constituents and other important actors on or away from movement issues." Awareness of mobilization leads to greater salience of issues and tactics. In other words, these are political opportunities that can be used to create a shared environment or political frame (Pride 1995). Others have labelled these "fateful" (Giddens 1991) or "focal" moments (Ganz 2000:1019), highlighting how they act as sudden changes that alter the life course of individuals or the strategic capacities of organizations to mobilize. Some, like McAdam and Sewell (2001), show how critical events act as poignant actions that lead to "transformative" moments that alter the trajectory of contention and the negotiation of social order.

The notion of a critical event in social movement analysis is far from new. Walsh and Warland (1983) examine the effects of a similar phenomenon, which they call "suddenly imposed grievances," on patterns of participation in the anti-nuclear protest movement. Snow et al. (1998) examine the affects of "quotidian disruption" on mobilization, and Killian (1984:779) does the same with the notions of spontaneity and emergence. He examines how "spontaneous" actions can trigger the "emergence" of warranted responses and mobilization. Thus, critical events by any name are worth examining. They are similar to signaling opportunities, which reflect a build up of grievances, but are different because they affect all actors in a movement simultaneously. Likewise, unlike other opportunities, which re-emerge 
in later cycles, critical events are limited by their immediacy and that is what gives them a greater salience. Therefore, they differ from political opportunities because they demand widespread response from all social actors and thus transcend differences across the movement spectrum.

In addition, this research questions how Meyer and Minkoff (2004), and for that matter, most social movement researchers, specify political opportunities in their regression analyses. Many assess the causal effects of political opportunity but ignore time by failing to lag measures of opportunity. Without doing so, there is little evidence of cause and effect, but rather proof of association controlling for a number of factors. To show cause, it is important to consider the timing of opportunities, showing that they come before given outcomes. To their credit, Meyer and Minkoff's "signaling" models take this into account, but not their structural models. Instead the latter treat opportunities as contemporaneous, save their measure of protest. To understand the causal impact of structural variables it is important to lag them too. Moreover, to understand how given factors work as signals to mobilize and influence, it is worth looking at more dynamic accounts of this process, which measure how much change occurs between periods, rather than lagged effects alone. Mere lagged counts do not capture change, only prior cause. Meyer and Minkoff (2004) partially account for this, but do so in only one measure rather than looking at change across all opportunities. Looking at rates of change in both structural and signaling variables better illustrates how changes in each trigger or inhibit mobilization. Moreover, Meyer and Minkoff's assessment of different types of opportunities mostly look at structural and signaling models separately, at times accounting for general opportunities in each, but failing to account for all measures simultaneously. As a result, it is difficult to compare one set of opportunities against the other. Including all types of political opportunity in a given model simultaneously, and treating them each as lagged or differenced, might shed light on which opportunities are most robust in accounting for given outcomes. Thus, one of the main goals of this paper is to assess how different specifications of opportunities influence results, if at all. Ultimately, this allows us to determine whether some opportunities and critical events robustly influence mobilization.

\section{A Brief History of Canadian Aboriginal Mobilization, 1951-2000}

Contemporary Canadian Aboriginal mobilization can be traced back to the large number of Aboriginal ${ }^{2}$ servicemen who returned from World War II and became increasingly politically active by questioning their colonization and treatment by the dominant Canadian society (Fleras and Elliott, 1992). They began to demand better educational opportunities, resources to 
develop communities, and respect from the federal government, asking that it honor past treaties and amend the Indian Act (Cardinal 1999). However, during the 1950s and 60s, there was little overt broad-based political mobilization. Instead, it was a period when many local grievances were resisted and organizations formed.

However, in 1969 the federal government released a policy brief proposing the elimination of Indian status, known as "The White Paper." It was a critical event marking the birth of contemporary Aboriginal mobilization and in retrospect signaled a new era (Long 1992; Ramos 2006, 2008; Wilkes 2006). Aboriginals responded to the White Paper with their own policy brief, which they called "The Red Paper" and the government acquiesced, leading to a policy vacuum on Aboriginal issues. During the 1970s, new Aboriginal political organizations began to take advantage of emerging political opportunities and pursued their rights through various legal avenues, many of which were surprisingly successful. However, at the same time the decade was also characterized by a number of radical protests.

During the early 1980s, Canada patriated its constitution, and nationallevel Aboriginal organizations were successful in lobbying for Section 35 in the Constitution Act 1982, which recognizes Aboriginal rights. A number of constitutional conferences were held between 1983 and 1987 to resolve outstanding issues with the constitution, and at the final conference, the Meech Lake Accord was negotiated, to be ratified in 1990. The Accord was to amend the Constitution to better incorporate the province of Quebec, but also dealt with broader issues such as Senate reform, immigration and Supreme Court appointments. Despite the Accord's grand vision, it led to opposition from the women's movement, trade unions, anti-poverty groups and Aboriginals. All felt their rights were ignored.

The summer of 1990 was particularly eventful for Aboriginal mobilization because June $23^{\text {rd }}$ was set as the deadline for each province to ratify the Meech Lake accord. Elijah Harper, an Aboriginal member of the Manitoba provincial legislature, with the support of other Aboriginal organizations, used his seat to stall the ratification process. Ultimately his actions opened debate and contributed to its demise. Later that summer, Mohawks in southern Quebec engaged in a 78-day armed standoff with authorities over a land dispute, which escalated to widespread protest by Aboriginals that year (Ramos 2006; Wilkes 2004a, 2004b). The rest of the decade and now the current period reflect both increasing institutional action by national organizations and, at the same time, the rise of more radical tactics by non-formally organized actors in local communities.

Recent years have yielded much success for Aboriginal mobilization in Canada, as can be seen in the reaffirmation of Aboriginal rights and traditional knowledge in the Nisga'a settlement of 2000. This can also be seen in a number of significant Supreme Court decisions supporting 
Aboriginal fishing rights and Métis hunting rights. At the same time, recent years have also been characterized by violent actions, such the standoffs and forceful state response at Ipperwash, Caledonia and Gustafsen Lake in Ontario and British Columbia. This is linked with a growing intolerance towards Aboriginal issues by the dominant population. As journalist Jeffrey Simpson notes, a paradoxical situation exists: "At a high level of abstraction, Canadians tell pollsters of their sympathy for aboriginals. That begins to wane as the issues become more concrete... As the years go on, fewer and fewer non-aboriginals feel guilty about past wrongs." (Simpson 1999) As a result, Canadian Aboriginals still struggle to gain social justice.

\section{Methods}

As noted above, Meyer (2004) and Meyer and Minkoff (2004) encourage social movement researchers to disaggregate outcomes and actors. In their analysis they look at differences in outcomes to mobilize and influence; in this article I will not analyze the ability to influence, but will rather compare outcomes to mobilize the contentious action of different social movement actors as well as the founding of different types of organizations. This extends their work by disaggregating each. In doing so, my analysis uses their framework of political opportunities, which differentiates among structural, signaling and general opportunities. It also adds measures of critical events and accounts for time and change in various model specifications.

\section{Dependent Variables: Contentious Action and Organizational Formation}

Like other studies examining contentious action over a long period of time, I collected data from a content analysis of newspaper coverage of given actions. Articles in the Globe and Mail were examined for the period 19512000. Those covering a contentious action and mentioning one or more of the following Aboriginal keywords: Native, Indian, Inuit, Eskimo and Métis were coded. Contentious action was broadly defined as any act outside the dominant political process with a clear target, actor, place, action and goal. If more than two of these were missing the article was not coded. Unlike models presented by Ramos (2006), the data in this analysis include media and legal actions in addition to protest and violent actions.

Contention was coded from the Globe and Mail because it is the longest running "national" Canadian newspaper and was indexed in the Globe Information Services CD-Rom (1991-2001) and Canadian News Index (1977-1990). Articles before 1977 were coded from the first section of each day's hard copy issue. Even though some have cautioned against using newspaper data to code events (Earl et al. 2004; Smith et al. 2001; McCarthy et al. 1996), and others note that Canadian media coverage of 
Aboriginal protest is skewed (Wilkes and Ricard 2007), and yet others warn against using a single source ${ }^{3}$ (Mueller 1997; Swank 2000; Koopmans and Rucht 2002), the coding of the Globe and Mail alone was the only feasible means of collecting data on contentious action for a 50-year period. Unlike those who intensively code the coverage of critical moments by different news sources, such as Rohlinger (2002), my approach allows for analysis over a long period of time, tracking macro ebbs and flows of contention. This provides wider historical analysis and would be more difficult to achieve if multiple sources were used.

A total of 948 actions were coded of which 166 (18\%) were actions by non- affiliated Aboriginals with no formal or explicit link to an organization, $46(5 \%)$ were by Traditionalists/ Warriors, $283(30 \%)$ by First Nations, 352 (37\%) by PanAboriginal organizations, 50 (5\%) by coalitions between Aboriginals and non-Aboriginal organizations and 51 (5\%) were actions by non-Aboriginals alone. With the exception of non-Aboriginals, each is treated as a dependent variable looking at the influence of various political opportunities and critical events on different Aboriginal actors. They represent a broad range of Canadian Aboriginal actors on a continuum of consistent champions and strategic respondents.

Non-Affiliated Aboriginals often act spontaneously and at other times in concert with wider mobilization. These are people who tend to act in an ad hoc manner, who do not necessarily represent existing organizations or other groups. Traditionalists/ Warriors, also tend to act regardless of political environment to preserve Aboriginal traditions and lands. They often act in disregard of the elected band councils of given reserves or First Nations. By contrast PanAboriginal organizations and coalitions of Aboriginals and other movements act more calculatively, taking advantage of shifts in policy and mainstream institutions. PanAboriginal organizations, such as the Assembly of First Nations that represents the elected chiefs of bands across the country, encompass broad constituencies transcending geographic, cultural, linguistic and other differences. Likewise, in the period under analysis there were a number of instances where Aboriginal groups acted in concert with other movements, such as environmentalists or women's organizations. Between the polls of consistent champions and strategic respondents are First Nations that act both to preserve Aboriginal traditions and lands regardless of context, but also are savvy political actors in the Canadian polity. First Nations actors are those that represent specific Aboriginal bands, communities or reserves. For comparison, in some models, the different actors are aggregated into the variable all Aboriginals, which is the sum of all actors acting contentiously in a given year.

I also examine how the formation of organizations is influenced by political opportunities and critical events. Following Couton and Cormier (2001), who code from the Quebec Gazette, I code organizational formation from 
those filing letters of patent in the Canada Gazette, Canada Corporations Bulletin and Canada Corporations Directorate. A total of 510 organizations mentioning Aboriginal keywords or the name of a recognized Aboriginal people or First Nation in the title, charter or amendment filed from 1951 through 2000 were coded. These were then aggregated into four different types of organization, including for example, 268 (53\%) service providers, those offering employment training or other social services; $125(25 \%)$ associations/clubs, which for the most part consist of social or cultural organizations; $112(22 \%)$ political organizations, or those which directly engage in political mandates, such as the Congress of Aboriginal Peoples at the national level or the Grand Council of the Cree at the local level; and $5(1 \%)$ other organizations that did not fit any of these groupings. (Because of rounding the percentages do not add to 100.) In addition, because of their small number, other organizations are excluded from disaggregated models run below. Like the measures of actors, these groupings also represent different points on the continuum of consistent champions and strategic respondents, with service organizations continually mobilizing regardless of political conditions and political organizations largely emerging in concert with favourable political contexts. Each type of organization is also aggregated into the variable all organizations.

Thus, models will examine how various political opportunities and critical events influence contentious action and organizational formation on a range of consistent champions and strategic respondents.

\section{Independent Variables: Structural, Signaling and General Opportunities and Critical Events}

Different types of political opportunity measures were identified by Meyer (2004) and Meyer and Minkoff (2004), including structural, signaling and general opportunities. Added to these, I argued it is also useful to examine critical events. To understand the role of structural opportunities, Indian and North Affairs Canada budgets are examined. In years prior to the creation of the department, estimates for Indian Affairs programs are used instead. Following Meyer and Minkoff (2004), who use annual government spending as a measure of structural opportunity, I also use levels of potential funding as such a measure. This is also similar to measures of transfer payments and per capita income used by Snow et al. (2005), who find that such measures offer insight into available resource pools, which contribute to mobilization. In fact, INAC allocates funds to Aboriginal organizations and also transfers them to reserves and First Nations, which in turn may use them directly or indirectly to mobilize people contentiously (Fleras and Elliott 1992; Tennant 1990). Thus, this measure offers insight 
into the wider economic and political structure. These data were gathered from federal budget estimates recorded in the Treasury Board Estimates, Part III, for each year, 1951-2000. Estimates were then transformed into constant 2000 Canadian dollars and aggregated by year. ${ }^{4}$ INAC budgets are expected to increase both contentious action by Aboriginals and the formation of new organizations.

A number of signaling opportunities are also included. Unlike more stagnant structural opportunities that change in broad ebbs and flows, these vary more rapidly, offer quicker and more visible rewards, and offer insight into changing political context. These are measured by three variables: average newspaper coverage, the number of land claims settled and Canadian Supreme Court decisions ruling on Aboriginal people(s) or issues. Average newspaper coverage of articles reporting on Aboriginal contentious action in a given year was coded from the Globe and Mail. These include articles on actions by non-Aboriginals on Indigenous issues not included in the current analysis. This was used as a measure of media or contextual openness to Aboriginal issues. Media prominence is associated with the ability to shape stories, communicate with potential supporters and generate resources (Koopmans and Olzak 2004; Ryan et al. 2001; Gamson and Wolfsfeld 1993). Meyer and Minkoff (2004), moreover, use a similar measure in their analysis of political opportunities. McCarthy et al. (1996) find that the news media tend to cover only a small fraction of actual protests. Like Ryan (1991) they find that most coverage is shaped by "news pegs" that provide limited space for coverage. If a movement receives less coverage its message is less likely to be heard and its ability to shape public discourse will be muted. By contrast, the more newsprint offered to their mobilization, the greater its salience and potential to persuade or recruit bystanders. Koopmans and Olzak (2004) find that media offer discursive opportunities for movements to diffuse their messages to broader publics. This in turn offers opportunities for movement visibility, resonance and legitimacy (Koopmans and Olzak 2004). The average length of coverage is thus used as a proxy of the discursive space and diffusion potential afforded to Aboriginal issues. It is thus anticipated that the longer the average length of articles covering contentious action in a given year, the more open the media and the greater the chance of mobilizing.

I also examine political-legal opportunities as a possible influence. This is done through the number of land claims settled in a given year. These data were obtained from email correspondence with INAC and from the Comprehensive Claims Policy and Status of Claims, February 2003 report (INAC 2005, 2003)..$^{5}$ Land claims play a significant role in Canadian Aboriginal mobilization and during the past 20 years there has been an explosion of legal scholarship looking at Aboriginal rights and treaties. Some of the most prominent instances of Canadian Aboriginal 
mobilization were based on legal rights. The settlement of land claims also generates resources for specific communities and demonstrates the fruitfulness of pursuing Aboriginal rights to others. Land claims have also been a central grievance for Aboriginals since colonization and for the most part remain largely unresolved. It is thus expected that as the number of land claims settled increase, contentious action will decrease but organization formation will increase. This is because their resolution eliminates a primary grievance for a number of Aboriginal actors, including Traditionalists/ Warriors and First Nations, but also leads to the availability of new resources and points of accessing the dominant polity which facilitate organization formation at all levels.

Political-legal opportunities arising from Supreme Court decisions ruling on Aboriginal peoples or issues are also considered. Supreme Court decisions during the 1951-2000 period mentioning Aboriginal keywords in the decision's "catchwords," "headnotes" or title were coded. The Lexis-Nexis database was used to search the Canadian Supreme Court Reports. A total of 108 decisions were coded and aggregated by year. Although some might consider looking at "critical" decisions instead of all decisions, I chose not to do this because of my interest in overall context over particular decisions. Moreover, there is much difficulty in quantifying "significant" decisions over others. Nevertheless, looking at the total number of decisions in a given year allows me to examine the volume of cases being processed and the use of the courts as a viable means to settle grievances. It provides a broad measure of the overall socio-legal context. The number of Supreme Court decisions in a given year is used as a measure of signaling opportunities because other social movement scholars also consider them important (Meyer and Minkoff 2004; Bashevkin 1996; McAdam 1982) and scholars looking at Aboriginal-Canadian relations largely credit Supreme Court decisions with opening the dominant polity for Aboriginal organizations and issues (Asch 1993; Fleras and Elliott 1992). Like land claims settled, the resolution of Supreme Court decisions are expected to decrease contentious action, but increase organizational formation.

A number of general opportunities are also considered. Unlike structural opportunities based in established institutions and which vary at a slow pace or signaling opportunities that offer visible cues for success or failure, general opportunities are those that exist as a result of the on going political process and are not necessarily movement or issue specific. These are measured by four dummy variables looking at years when a new prime minister was sworn into office, years of federal elections, years when a new INAC minister was sworn in, and years of Conservative regimes. These measures were chosen to reflect those used by Meyer and Minkoff (2004) but also to include factors that 
Table 1: Summary Statistics

\begin{tabular}{lcc}
\hline Variables & Mean & Std. Dev. \\
\hline Dependent Variables for Contentious Actors & & \\
$\quad$ All Aboriginals & 16.96 & 18.5483 \\
Non-affiliated Aboriginals & 3.32 & 5.0404 \\
Traditionalists/warriors & .92 & 1.6884 \\
$\quad$ First nations & 5.66 & 7.0901 \\
$\quad$ Pan-Aboriginal organizations & 7.04 & 6.1973 \\
$\quad$ Coalition Aboriginals/ Non-Aboriginals & 1 & 1.9272 \\
Dependent Variables for Organizations Founded & & \\
All organizations & 10.2 & 12.3487 \\
$\quad$ Service providers & 5.36 & 7.4963 \\
Associations/clubs & 2.5 & 3.0119 \\
$\quad$ Political & 2.24 & 2.7446 \\
Independent Variable: Structural Opportunities & & \\
INAC budget, in millions & 2411.752 & 1806.5730 \\
Independent Variables: Signaling Opportunities & & \\
Average newspaper & 9.04 & 3.4539 \\
$\quad$ Land claims settled & 4.84 & 8.2347 \\
$\quad$ Supreme Court decisions & 2.16 & 2.3764 \\
Independent Variables: General Opportunities & & \\
$\quad$ Prime Minister sworn in & .14 & .3505 \\
$\quad$ Federal election & .32 & .4712 \\
$\quad$ New INAC minister & .4 & .4949 \\
Conservative regime & .32 & .4712 \\
Independent Variables: Critical Events & & \\
$\quad$ All Aboriginal actors year & .18 & .3881 \\
Critical event year & .06 & .2399 \\
\hline
\end{tabular}

potentially influence Canadian Aboriginal mobilization. Data on new prime ministers were gathered from the Parliament of Canada web site, listing the prime ministers of Canada 1867 to present, as were Federal elections. Analysis of INAC ministers is included because of the large amount of resources they oversee and because the ministry is responsible for the governance of much of Canadian Aboriginal people's lives. ${ }^{6}$ These data were coded from the INAC website. The last general opportunity analyzed are years of federally elected conservative regimes. These were coded for two reasons. First, only 16 years of the period examined were ruled by Conservative federal governments; and second, some of the most poignant moments of contemporary Aboriginal-Canadian relations were under their regimes. Each general opportunity is expected to increase contentious action and organizational formation.

I also believe it is useful to consider critical events or opportunities that affect all actors in a movement spectrum simultaneously. To analyze 
this, two additional dummy variables are examined: all Aboriginal actors and critical event years. All Aboriginal actor years are those when each of the Aboriginal actors in the Canadian Aboriginal movement spectrum acted contentiously. Only nine years had actions by all Aboriginal actors. Most movements operate with various consistent champions constantly mobilizing and strategic respondents picking and choosing when to act. However, years when all actors on the continuum of contentious actors converge indicate widespread grievance and operate as signals of changing opportunities. Three specific critical event years are also examined: 1969, 1982 and 1990. These were chosen because they represent transformative moments outlined in the section dealing with the brief history of Canadian Aboriginal mobilization. Both critical event measures are expected to increase contentious action and organizational formation.

Regression analysis was used to examine the influences of structural, signaling and general opportunities, as well as critical events, on contentious action and organization formation by Canadian Aboriginals. Because the dependent variables are yearly counts of contentious action by given actors and organizational formations, negative binomial regression models were used. These methods were used in place of Poisson models because diagnostics identified significant over-dispersion which is addressed by negative binomial regression (Cameron and Trivedi 1986; King 1989; Long 1997).

It is important to consider time sequence in causal explanations of political opportunity, and it is worth exploring dynamic measures of change to account for signaling. To engage these issues, two additional series of models are reported, those using lags of one year for all the independent variables and another set accounting for change by reporting differences in values from one year to the next. These are examined against contemporaneous base models that do not account for either, to see how various political opportunities perform and to assess whether some consistently affect actors and organizations in the same way across the Canadian Aboriginal movement spectrum. Because of the large number of models run, summary results are reported in Tables 2 and 3 that use "+" and "-"symbols to signify statistically significant positive and negative effects on different contentious actors and organization formations. Full models and syntax are available upon request to the author. Thus, the goal of this research is exploratory rather than confirmatory.

\section{Analysis and Discussion}

During the 1951-2000 time period, many political opportunities emerged for Canadian Aboriginals. As Figure 1 illustrates, the rates of contentious action and organizational formation fluctuated considerably during this 
period and much of it occurs at moments of shifting opportunities. On the structural level, INAC budgets gradually increased during the later half of the $20^{\text {th }}$ century. Significant changes occurred in 1966 when the department was formed out of sub-branches of Citizenship and Immigration and Northern Affairs and National Resources, consolidating resources allocated to Aboriginal affairs and representing significant changes in how the federal government intended to engage Aboriginal issues. Just two years after this shift, the rate of Aboriginal contentious action doubled that of any previous year, thus structural opportunities might account for this.

If one considers signaling opportunities, the first contemporary land claim was settled with the James Bay and Northern Quebec Agreement in 1975, perhaps accounting for increased contentious action and organization in the 1970s. During the same time period a number of important Supreme Court decisions were reached, such as Calder in 1973, which could have also contributed to these trends. Thus, signaling

Figure 1. Canadian Aboriginal Contentious Action and Organization Formation, 1951-2000



$\longrightarrow$ Contentious Action

-....... Organization Formation 


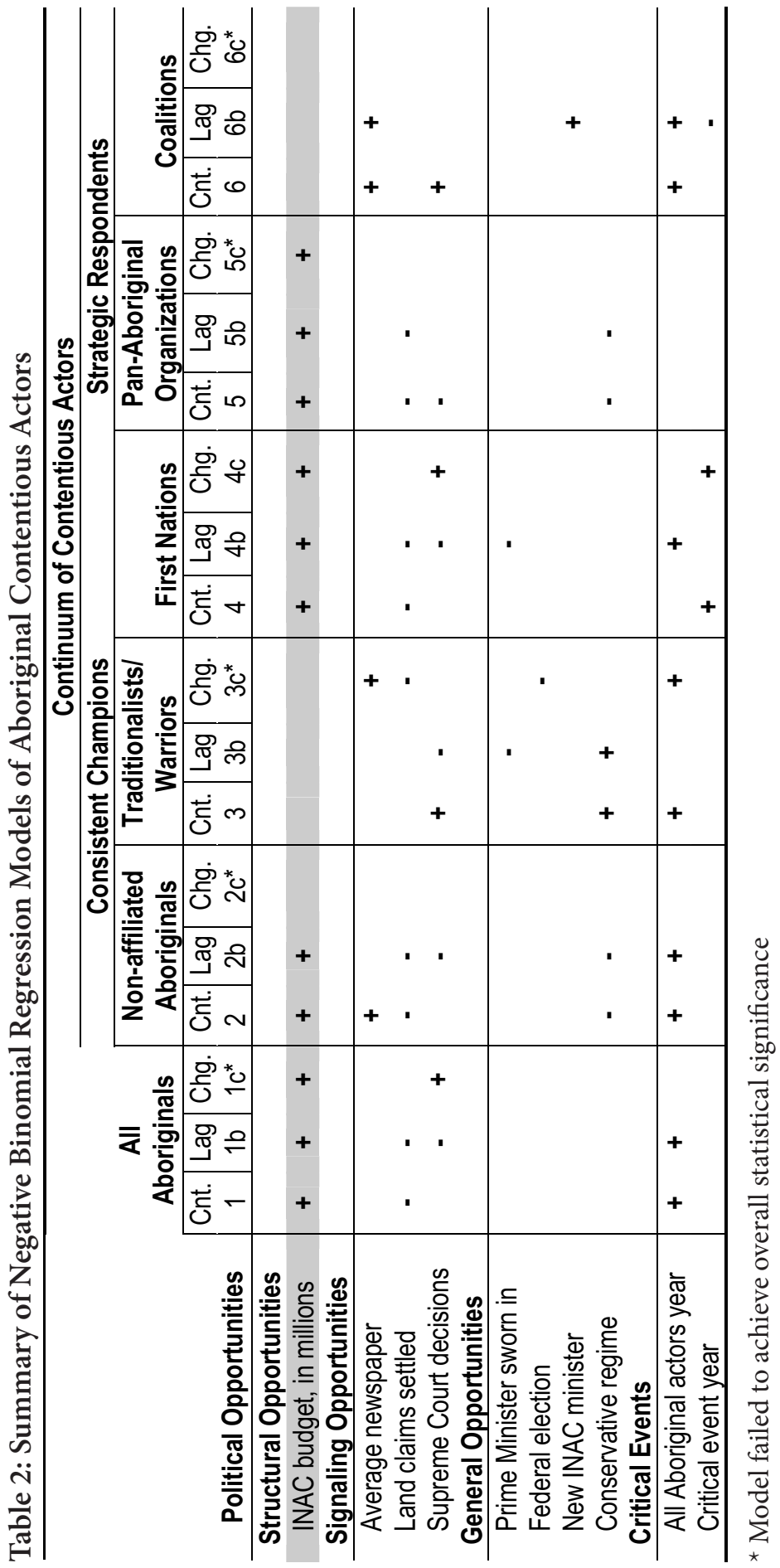


opportunities might account for changing rates of mobilization. Yet, at the same time, general opportunities might also explain shifting patterns too. There were a number of short-lived governments in the late 1970s and early 80s, leading to shifts in prime ministers, federal elections and new INAC ministers. This might account for changing rates of contentious action and organization then. However, a critical event also emerged in the early 1980s with the patriation of the Constitution, perhaps accounting for increased contentious action, followed by the formation of a number of new organizations. The same pattern can also be observed around 1990, with the Meech Lake Accord, which attempted to amend the Constitution. As result, structural, signaling and general opportunities as well as critical events might all account for changing rates of mobilization. One of the goals of this paper is to better understand which ones do and how they affect a broad spectrum of movement actors and organizations.

When different Aboriginal actors are regressed on measures of structural, signaling and general political opportunities as well as critical events, a hodgepodge of different opportunities are statistically significant in their influence of Aboriginal contentious action. There is little consistency in effects across actors. Models treating opportunities contemporaneously are used as bases for comparison with other specifications accounting for lagged and change measures.

In general, models 1-6 of Table 2 show that INAC budgets increased the contentious action for the aggregate measure of Aboriginal mobilization as well as that of non-affiliated Aboriginals, First Nations and PanAboriginal organizations, illustrating that both consistent champions and strategic respondents are influenced by structural opportunities. Media coverage significantly increased action by non-affiliated Aboriginals and coalitions alone. Land claims settled decreased the number of actions for the aggregate measure as well as non-affiliated Aboriginals, First Nations and PanAboriginal organizations illustrating that these grievances drive both consistent champions of Canadian Aboriginal mobilization and strategic respondents. Supreme Court decisions significantly increased the actions of Traditionalists/Warriors and those participating in coalitions; however, it decreased action by PanAboriginal organizations. It appears that signaling opportunities both increase and decrease contentious action. Conservative regimes were the only statistically significant general measure of political opportunity and were significant for only non-affiliated Aboriginals, Traditionalists/ Warriors, and PanAboriginal organizations. However, it worked in opposite directions across these actors, decreasing action by nonaffiliated Aboriginals and PanAboriginal organizations but increasing that of Traditionalists/Warriors. Last, years experiencing widespread mobilization increased the contentious action of the aggregate of all Aboriginals, nonaffiliated Aboriginals, Traditionalists/Warriors, and coalitions. Critical event 
years were significantly related only to increased actions of First Nations. It appears that widespread mobilization encourages both consistent champions and strategic respondents, whereas as critical junctures spark mobilization of those in the middle of the continuum.

When organization formation is regressed on the same political opportunities, in Table 3, models 7-10, one again finds differences in the ways

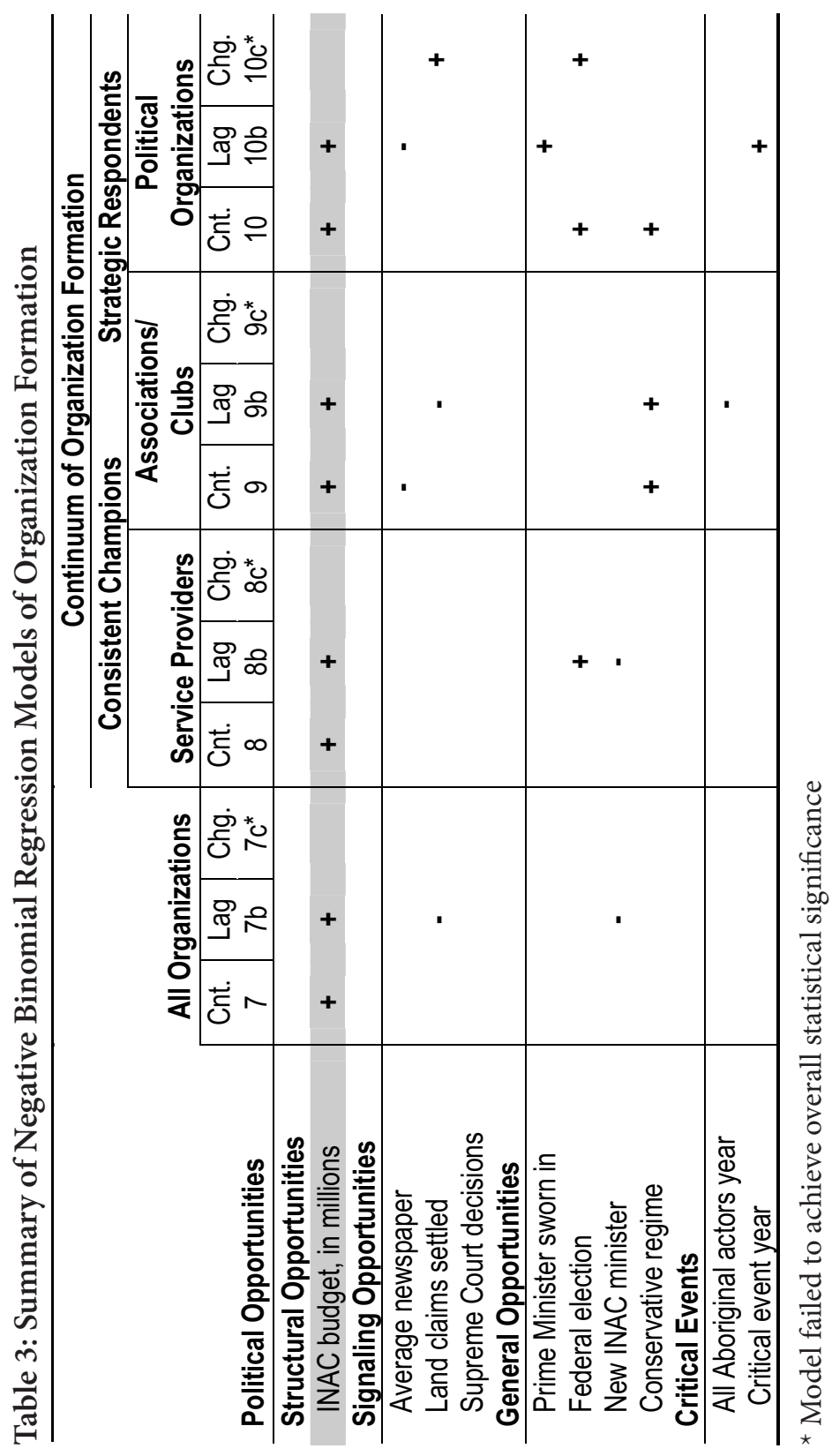


political opportunities relate to the founding of different types of organizations. INAC budgets were the most consistent influence of organizational formation, significantly increasing the founding of all types of organization.

Average newspaper coverage had a negative impact on the formation of associations/ clubs, but did not have a statistically discernable effect on the formation of other types of organizations. Federal election years increased the founding of political organizations alone. And, the formation of associations/ clubs and political organizations increased during years with conservative regimes. Other opportunities do not appear to have statistically significant effects on organizational formation. These findings make intuitive sense. Budgets or structural opportunities affect the broadest range of organizational formation, signaling opportunities appear to have little effect on organizations, save associations/clubs, and general opportunities affected various actors differently. As one might expect, it also appears that organizations in the middle to strategic respondent side of the continuum of movement actors respond to more opportunities than consistent champions.

The findings of both series of contemporaneous base models, looking at actors and organizational formation, are similar to the wide ranging and often conflicting results reported in the dominant literature. Nevertheless, resources or structural opportunities appear to have the most consistent impact across various consistent champions and strategic respondents. As we will see, this becomes even clearer when time is factored into the specification.

Models $1 \mathrm{~b}-6 \mathrm{~b}$ of Table 2, examine time by looking at rates of contention by different Aboriginal actors on lagged political opportunities. ${ }^{7}$ Rather than interpreting the effects of each model, what is striking are the similarities found across them. Again structural opportunities measured by INAC budgets and signaling opportunities measured by land claims settled are statistically significant and share similar effects across Aboriginal actors. INAC budgets increase contentious action of all actors and land claims settled decreases it, with the exception of Traditionalists/ Warriors and coalitions between Aboriginals and non-Aboriginals.

Other measures vary across models. For example, average newspaper coverage increased the action of only coalitions. The action of the aggregate measure of all Aboriginals, non-affiliated Aboriginals, Traditionalists/Warriors and First Nations decreased with Supreme Court decisions. Years when prime ministers are sworn in decrease contention for Traditionalists/Warriors and First Nations. New INAC ministers have the opposite effect on action by coalitions. Conservative regimes significantly decreased the actions of non-affiliated Aboriginals and PanAboriginal organizations but increased those of Traditionalists/ Warriors. In addition, years when all Aboriginals acted contentiously significantly increased the actions of all actors, save 
Traditionalists/Warriors and PanAboriginal organizations; critical event years significantly decreased the actions of coalitions alone.

It appears that structural and signaling opportunities robustly affect various Aboriginal actors, general opportunities have varying effects and critical events have mixed results. In both the base contemporaneous and time regressions, Traditionalists/ Warriors (models 3 and $3 \mathrm{~b}$ ) responded more to general opportunities and strategic respondents like PanAboriginal organizations (models 5 and $5 b$ ) seem to be swayed by structural and signaling opportunities, confirming claims by Meyer (2004).

When time is considered with the rate of forming new organizations in Models 7b-10b of Table 3, we again find that structural opportunities, measured by INAC budgets, increases mobilization of all aggregates of organization formation. Average newspaper coverage significantly decreases the formation of political organizations, and the number of land claims settled decreases the aggregate measure of organizational formation and that of associations/ clubs. New prime ministers increase political organization, federal election years increase the formation of service providers, and new INAC ministers decrease the aggregate measure and that of service providers. Associations/clubs significantly increase their rates of founding when Conservative regimes are in power and critical events are poorly supported, with all Aboriginal actor years decreasing the founding of associations/clubs and specific event years increasing political organization formation.

As a result, when time is modeled in a causal sequence, INAC budgets or structural opportunities increase both forms of mobilization and do so consistently across the movement spectrum of consistent champions and strategic respondents. Signaling opportunities seem to hold more salience for contentious actors and general opportunities have mixed influences on various actors and organizations. Critical events appear to be more important for the action of different actors rather than organization formation and are thus only modestly supported by these models.

When change is modeled by looking at fluctuations in measures of political opportunity, results are much less clear-cut and models are rather weak. Models $1 \mathrm{c}-6 \mathrm{c}$ of Table 2 regress various Aboriginal contentious actors on changes in structural, signaling, and general political opportunities as well as critical events. Only Model 4c achieves overall statistical significance and thus other models will not be discussed. Changes in INAC budgets significantly increased the contentious action First Nations, as did Supreme Court decisions and critical event years. These results continue to illustrate the importance of structural opportunities, but show that signaling opportunities and critical events work differently when change is considered and there is little support for the influence of general opportunities on contentious actors. However, these models are much 
weaker than those accounting for time, with lower Wald $x^{2}$ values, and most models failing to achieve overall statistical significance. In terms of the consistent champion and strategic respondent continuum, First Nations who fall somewhere in the middle of it, were the only actors to significantly respond to changes in opportunities. Models 7c-10c of Table 3 assess the effects of change in political opportunities on organizational formation. Results from these models are weak, with none achieving overall statistical significance. It would appear that changes in opportunities have little significant impact on the formation of new organizations.

Nevertheless, when interpreted against the base contemporaneous models and those accounting for time, results become quite revealing. Various specifications of opportunities and critical events illustrate a number of interesting points. First, structural opportunities are robust across different model specifications. With the exception of those accounting for change, they increased contentious action for most Aboriginal actors and all types of organization formation, illustrating that they influence a broad range of consistent champions and strategic respondents. Second, signaling opportunities appear to influence contentious action more than organizational formation. Third, general opportunities appear to have mixed influence on estimating fluctuations in contentious action and organizational formation. And last, critical events gain only partial support in the models reported, but do seem to have a greater impact on contentious actors than organizational formation.

As a whole, specification matters. Models accounting for time by including lags allow researchers to make stronger claims on the causal sequence of opportunities, whereas those considering change yield weak results and poor model fits, suggesting that political opportunities may act more structurally than as signals per se. By looking at how different opportunities affect various actors and organizations, controlling for structural, signaling and general opportunities simultaneously, as well as accounting for critical events, we find what Meyer (2004) might have predicted - that strategic respondents rather than consistent champions respond more instrumentally to political opportunity. However, some opportunities perform more consistently across actors and organizations than others, and these should be of specific interest to those studying social movements. The most consistent measure was the amount of potentially available resources, measured by INAC budgets, which increased almost all forms of mobilization.

\section{Conclusion}

This paper responds to Meyer (2004) and Meyer and Minkoff's (2004) proposal to disaggregate movement outcomes and political opportunities in order to better understand how underlying mechanisms work. In doing 
so, they urge researchers to ask: political opportunity for what and for whom? Their work concentrates on the former, but has not yet fully examined the latter.

This research extended Meyer and Minkoff's original model by disaggregating different actors and organizations and analyzing the potential impact of critical events. Moreover, it examined how different model specifications accounting for time and change influence the way political opportunities affect different elements of the movement.

Disaggregation of actors and organizations offers insight into how opportunities work. As Meyer (2004) might have predicted, analysis of Canadian Aboriginal mobilization shows that consistent champions appear to respond the least instrumentally to opportunities, and strategic respondents the most. Comparing and contrasting different model specifications, controlling for all opportunities simultaneously, and disaggregating different actors and organizational formations shows that structural opportunities consistently increase a wide range of mobilization, signaling variables affect contentious action more, and general opportunities have mixed effects. The role of critical events appears more important for action than organization formation. Disaggregation ultimately generates parsimony. It identifies core opportunities that influence a broad spectrum of mobilizers and identifies factors that deserve further attention.

The importance of resources as a structural opportunity for Canadian Aboriginal mobilization is indeed a key finding and is very much in line with recent scholarship looking at other social movements. Much recent research finds that when controlling for other measures of political opportunity, material resources consistently affect patterns of mobilization. For example, McCammon (2001) concludes that structural economic factors influence the willingness of workers to file unfair labor charges rather than political conditions, organizational strength or the availability of alternate strategies. Snow et al. (2005) arrive at a similar conclusion, finding that larger monetary resource pools are associated with increased homeless protest. Soule et al. (1999) also find that resources are important to the mobilization of the American Women's movement over other opening and closing political opportunities.

Resources are also important for other Canadian social movements. Vickers et al. (1993), for example, highlight the role of government funding in the English-Canadian women's movement and the National Action Committee on the Status of Women. They find that debates over dependency on government resources were central in its mobilization. This is also illustrated by Bashevkin (1996) who found that NAC's status as the voice of English-Canadian women was seriously challenged when a conservative women's organization, Realistic, Equal, Active for Life. Women, began to contest their funding in the late 1980s. In fact, the 
availability of federal funding is likely to play a key role in other Canadian social movements and deserves further inquiry.

However, the importance of structural opportunities, and in particular resources, is only partially engaged by measures such as the availability of government funding for a particular issue or social movement. INAC budgets, for example, are but one form of potential resources available to Canadian Aboriginals. Those budgets contribute not only to increased contentious action, but also help facilitate broader engagement in the mainstream political process. My study was limited in its focus, concentrating on mobilization outcomes and not those of influence. To understand the potential impact of resources on the ability of movements to participate in dominant politics, such analysis is much needed. The negative effects of land claims on contentious action are indicative of the potentially complex way resources contribute to this process. They eliminate a key source of grievance for Aboriginals and are, at the same time, resources that clearly lead to more stability in Aboriginal-Canadian relations.

The methodological extensions of Meyer and Minkoff's work illustrate that specification influences results. Models that control for various opportunities simultaneously allow researchers to better understand which factors are most robust in their impact on various contentious actors and the formation of different types of organizations. Specifications that account for time allow researchers to make stronger claims on the effects of political opportunities on various mobilizers. Likewise, the weakness of models accounting for change suggest that political opportunities might work at a more structural or contextual level rather than as direct signals for change. Political opportunities might operate as slower structural processes associated with institutional cycles rather than immediate triggers that induce contention or organization. Critical events were modestly supported by this exploratory analysis and further examination is warranted.

Overall, the paper illustrates that the main questions social movement researchers need to engage are: which opportunities perform most consistently across a broad range of movement actors and organizations? And, which perform most consistently across methodological specifications? Addressing these questions will highlight core findings that transcend differences in movements and across the spectrum of consistent champions and strategic respondents. As McAdam, Tarrow and Tilly (2001) note, social movement research will advance only with the identification of underlying mechanisms that work consistently over a wide range of cases. Analysis of Canadian Aboriginal mobilization illustrates that when identifying differences, common patterns indeed emerge and consistent influences of mobilization become apparent. 


\section{Notes}

1. Others, such as Goodwin and Jasper (1999:30) peg political opportunity's origins earlier with Robert K. Merton's notion of "opportunity structure," but note that he is often overlooked in the social movement literature.

2. In this article I use the terms Aboriginal and Aboriginal peoples to refer to status Indians (First Nations), non-status Indians, Inuit and Métis. With the exception of non-status Indians, Section 35 of the Constitution Act, 1982 recognizes each of these groups as Aboriginal and it is for this reason that I use these terms. It should be noted, however, that some scholars are critical of the colonial elements that remain embedded in such recognition and terminology (see Alfred 1999). Additionally, international discourse often refers to Aboriginals as indigenous (or indigenous peoples) (Wilkes 2006). Nevertheless, given the examination of the Canadian context, I will use terms that are prominent within it.

3. Koopmans and Rucht (2002) note that a single source does not allow researchers to control for qualitative source biases. However, as Ramos (2006) illustrates, the amount of bias in Globe and Mail coverage is in line with other metrics such as organization formation and population. An excellent review of these issues, pertaining to Canadian Aboriginal protest, is found in Wilkes and Ricard (2007).

4. These data correct the measure used by Ramos $(2006,2004)$ which used budgets weighted by average inflation.

5. The file received from INAC included data on specific claims from only 1970 onward. However, Canada did not have a specifics claims policy until 1973 (Last accessed Nov. 7, 2007 at: http://www.ainc-inac.gc.ca/pr/info/info121_e.html). Moreover, the federal government was unwilling to negotiate comprehensive claims until after the Supreme Court's Calder decision during the same year and the first comprehensive claim documented was in 1975 (INAC 2003). As a result, it was assumed that no claims were settled before years of available data.

6. INAC only came into existence as a department in 1966. Before this Aboriginal affairs were administered under two departments, Citizenship and Immigration as well as Northern Affairs and National Resources. For years prior to 1966, Ministers under Citizenship and Immigration are coded. These were coded instead of Northern Affairs ministers because of the large population of status-Indians under their domain. (http://www.ainc-inac.gc.ca/ pr/info/irp_e.html).

7. It should be noted that the overall statistical significance Model 3b of Table 2 is only $p=.06$; all other models, unless otherwise noted, are significant at the .01 level. 


\section{References}

Alfred, Taiaiake. 1999. Peace, Power, Righteousness: An Indigenous Manifesto. Oxford University Press.

Amenta, Edwin, and Yvonne Zylan. 1991 "It Happened Here: Political Opportunity, the New Institutionalism, and the Townsend Movement." American Sociological Review 56(2):250-65.

Asch, Michael. 1993. Home and Native Land: Aboriginal Rights and the Canadian Constitution. University of British Columbia Press.

Bashevkin, Sylvia. 1996. "Losing Common Ground: Feminists, Conservatives and Public Policy in Canada during the Mulroney Years." Canadian Journal of Political Science 29(2):211-42.

Boudreau, Vincent. 1996. "Northern Theory, Southern Protest: Opportunity Structure Analysis in Cross-National Perspective." Mobilization 1(2):175-89.

Cameron, A. Colin, and Pravin K. Trivedi. 1986. "Econometric Models Based on Count Data: Comparisons and Applications of Some Estimators and Tests." Journal of Applied Econometrics 1(1):29-53.

Cardinal, Harold. 1999. The Unjust Society. Douglas \& Mclntyre.

Couton, Philippe, and Jeffrey Cormier. 2001."Voluntary Associations and State Expansion in Quebec 1955-1970." Journal of Political and Military Sociology 29(1):19-45.

della Porta, Donatella. 1995. Social Movements, Political Violence, and the State: a Comparative Analysis of Italy and Germany. Cambridge University Press.

Earl, Jennifer, Andrew Martin, John D. McCarthy and Sarah A. Soule. 2004. "The Use of Newspaper Data in the Study of Collective Action." Annual Review of Sociology 30:65-80.

Eisinger, Peter K. 1973. "The Conditions of Protest Behavior in American Cities." American Political Science Review 67(1):11-28.

Fleras, Augie, and Jean Leonard Elliott. 1992. The "Nations Within": AboriginalState Relations in Canada, the United States and New Zealand. Oxford University Press.

Gamson, William A., and David S. Meyer. 1996. "Framing Political Opportunity," Pp. 275-90. Comparative Perspectives on Social Movements: Political Opportunities, Mobilizing Structures, and Cultural Framings. Doug McAdam, John D. McCarthy and Mayer N. Zald, editors. Cambridge University Press.

Gamson, William A., and Gadi Wolfsfeld. 1993. "Movements and Media as Interacting Systems." Annals of the American Academy of Political and Social Science 528(July):114-25. 
Ganz, Marshall. 2000. "Resources and Resourcefulness: Strategic Capacity in the Unionization of California Agriculture, 1959-1966." American Journal of Sociology 105(4):1003-62.

Giddens, Anthony. 1991. Modernity and Self-Identity: Self and Society in the Late Modern Age. Stanford University Press.

Goldstone, Jack A., and Charles Tilly. 2001. "Threat (and Opportunity): Popular Action and State Response in the Dynamics of Contentious Action." Pp. 17994. Silence and Voice in the Study of Contentious Politics. Ronald R. Aminzade, Jack A. Goldstone, Doug McAdam, Elizabeth J. Perry, William H. Sewell Jr., Sidney Tarrow and Charles Tilly, editors. Cambridge University Press.

Goodwin, Jeff, and James M. Jasper. 1999. "Caught in a Winding, Snarling Vine: The Structural Bias of Political Process Theory." Sociological Forum 14(1):27-54.

Indian and Northern Affairs Canada. 2005. Personal e-mail correspondence with Indian and Northern Affairs Canada, Rosa Maria Navas at navasr@ainc-inac.gc.ca.

. 2003. "Comprehensive Claims Policy and Status of Claims, February 2003." Personal e-mail correspondence with Indian and Northern Affairs Canada, Rosa Maria Navas at navasr@ainc-inac.gc.ca.

Killian, Lewis M. 1984. "Organization, Rationality and Spontaneity in the Civil Rights Movement." American Sociological Review 49(6):770-83.

King, Gary. 1989. "Variance Specification in Event Count Models: From Restrictive Assumptions to a Generalized Estimator." American Journal of Political Science 33(3):762-84.

Kitschelt, Herbert P. 1986. "Political Opportunity Structures and Political Protest: Anti-Nuclear Movements in Four Democracies." British Journal of Political Science 16(1):57-85.

Koopmans, Ruud, and Susan Olzak. 2004. "Discursive Opportunities and the Evolution of Right-Wing Violence in Germany." American Journal of Sociology 110(1):198-230.

Koopmans, Ruud, and Dieter Rucht. 2002. "Protest Event Analysis." Pp. 23159. Methods of Social Movement Research. Bert Klandermans and Suzanne Staggenborg, editors. University of Minnesota Press.

Long, David. 1992. "Culture, Ideology, and Militancy: The Movement of Native Indians in Canada, 1969-1991." Pp. 118-34. Organizing Dissent: Contemporary Social Movements in Theory and Practice. William K. Carroll, editor. Garamond Press.

Long, J. Scott. 1997. Regression Models for Categorical and Limited Dependent Variables. Sage Publications. 
McAdam, Doug. 1982. Political Process and the Development of Black Insurgency, 1930-1970. University of Chicago Press.

McAdam, Doug, and William H. Sewell, Jr. 2001. "It's About Time: Temporality in the Study of Social Movements and Revolution." Pp. 89-125. Silence and Voice in the Study of Contentious Politics. Ronald R. Aminzade, Jack A. Goldstone, Doug McAdam, Elizabeth J. Perry, William H. Sewell Jr., Sidney Tarrow and Charles Tilly, editors. Cambridge University Press.

McAdam, Doug, Sidney Tarrow and Charles Tilly. 2001. Dynamics of Contention. Cambridge University Press.

McCammon, Holly J. 2001. "Labor's Legal Mobilization: Why and When Do Workers File Unfair Labor Practices?" Work and Occupations 28(2):143-75.

McCammon, Holly J., Karen E. Campbell, Ellen M. Granberg and Christine Mowery. 2001. "How Movements Win: Gendered Opportunity Structures and U.S. Women's Suffrage Movements, 1866 to 1919." American Sociological Review 66(1):49-70.

McCarthy, John D., Clark McPhail and Jackie Smith. 1996. "Images of Protest: Dimensions of Selection Bias in Media Coverage of Washington Demonstrations, 1982 and 1991." American Sociological Review 61(3):478-99.

Meyer, David S. 2004."Protest and Political Opportunities." Annual Review of Sociology 30:125-45.

Meyer, David S., and Debra C. Minkoff. 2004."Conceptualizing Political Opportunity." Social Forces 82(4):1457-92.

Meyer, David S., and Suzanne Staggenborg. 1996. "Movements, Countermovements, and the Structure of Political Opportunity." American Journal of Sociology 101(6):1628-60.

Mueller, Carol. 1997. "International Press Coverage of East German Protest Events, 1989." American Sociological Review 62(5):820-32.

Pride, Richard A. 1995. "How Activists and Media Frame Social Problems: Critical Events Versus Performance Trends for Schools." Political Communication 12(1):5-26.

Ramos, Howard. 2008. "Aboriginal Protest." Pp. 55-70. Social Movements. Suzanne Staggenborg, author. Oxford University Press.

2006. What Causes Canadian Aboriginal Protest? Examining Resources, Opportunities and Identity, 1951-2000." Canadian Journal of Sociology 31(2):211-34.

2004. "Divergent Paths: Aboriginal Mobilization in Canada, 1951-2000." Ph.D dissertation, Department of Sociology, McGill University, Montreal, Quebec. 
Rohlinger, Deana A. 2002. "Framing the Abortion Debate: Organizational Resources, Media Strategies, and Movement-Countermovement Dynamics." Sociological Quarterly 43(4):479-507.

Ryan, Charlotte. 1991. Prime Time Activism: Media Strategies for Grassroots Organizing. South End Press.

Ryan, Charlotte, Kevin M. Carragee and William Meinhofer. 2001. "Theory into Practice: Framing, the News Media, and Collective Action." Journal of Broadcasting \& Electronic Media 45(1):175-82.

Simpson, Jeffrey. 1999. "The Cost of Expectations." Globe and Mail. 29 Oct, A19.

Smith, Jackie, John D. McCarthy, Clark McPhail and Boguslaw Augustyn. 2001. "From Protest to Agenda Building: Description Bias in Media Coverage of Protest Events in Washington, D.C." Social Forces 79(4):1397-423.

Snow, David A., Daniel M. Cress, Liam Downey and Andrew W. Jones. 1998. "Disrupting the 'Quotidian": Reconceptualizing the Relationship Between Breakdown and the Emergence of Collective Action." Mobilization 3(1):1-22.

Snow, David A., Sarah A. Soule and Daniel M Cress. 2005. "Identifying the Precipitants of Homeless Protest Across 17 U.S. Cities, 1980 to 1990." Social Forces 83(3):1183-210.

Soule, Sarah A., and Brayden G. King. 2006. "The Stages of the Policy Process and the Equal Rights Amendment, 1972-1982." American Journal of Sociology 111(6):1871-909.

Soule, Sarah, Doug McAdam, John D. McCarthy and Yang Su. 1999. "Protest Events: Cause or Consequence of State Action? The U.S. Women's Movement and Federal Congressional Activities, 1956-79." Mobilization 4(2):239-56.

Staggenborg, Suzanne. 1993. "Critical Events and the Mobilization of the ProChoice Movement." Research in Political Sociology 6:319-45.

Swank, Eric. 2000. "In Newspapers We Trust? Assessing the Credibility of News Sources That Cover Protest Campaigns." Research in Social Movements, Conflicts and Change 22:27-52.

Tarrow, Sidney. 1998. Power in Movement: Social Movements and Contentious Politics. $2^{\text {nd }}$ edition. Cambridge University Press.

1989. Democracy and Disorder: Protest and Politics in Italy, 1965-1975. Clarendon Press.

. 1988. "National Politics and Collective Action: Recent Theory and Research in Western Europe and the United States." Annual Review of Sociology 14:421-40. 
Tennant, Paul. 1990. Aboriginal Peoples and Politics: The Indian Land Question in British Columbia, 1849-1989. University of British Columbia Press.

Tilly, Charles. 1978. From Mobilization to Revolution. Addison-Wesley.

Van Dyke, Nella, and Sarah A. Soule. 2002. "Structural Social Change and the Mobilizing Effect of Threat: Explaining Levels of Patriot and Militia Organizing in the United States." Social Problems 49(4):497-520.

Vickers, Jill, Pauline Rankin and Christine Appelle. 1993. Politics as if Women Mattered: A Political Analysis of the National Action Committee on the Status of Women. University of Toronto Press.

Walsh, Edward J., and Rex H. Warland. 1983. "Social Movement Involvement in the Wake of a Nuclear Accident: Activists and Free Riders in the TMI Area." American Sociological Review 48(6):764-80.

Wilkes, Rima. 2006. "The Protest Actions of Indigenous Peoples: A Canadian-U.S. Comparison of Social Movement Emergence." American Behavioral Scientist 50(4):510-25.

2004a. "First Nation Politics: Deprivation, Resources, and Participation in Collective Action." Sociological Inquiry 74(4):570-89.

2004b. "A Systematic Approach to Studying Indigenous Politics: BandLevel Mobilization in Canada, 1981-2000." The Social Science Journal 41(3):447-57.

Wilkes, Rima, and Danielle Ricard. 2007. "How Does Newspaper Coverage of Collective Action Vary? Protest by Indigenous People in Canada." The Social Science Journal 44(2):231-51. 